\title{
Structural Investigation of UV Aged Tent Fabrics
}

\author{
Emrah Temel ${ }^{1}$, Faruk Bozdoğan ${ }^{1}$, Deniz Mizmizlioğlu ${ }^{2}$ \\ ${ }^{1}$ Ege University, Engineering Faculty, Textile Engineering Department, İzmir, Turkey \\ ${ }^{2}$ Ege University, Institute of Science, Textile Engineering Department, İzmir, Turkey
}

Corresponding Author: Emrah Temel, textile.temel@gmail.com

\begin{abstract}
Emergency tent is a basic human need and a critical determinant for survival and coping in the majority of crises. There are many reasons people might need temporary shelters. Natural disasters like hurricanes, earthquakes, floods, fires, and tornados are some of them. Millions of people around the globe have had their lives disrupted by these disasters. The environmental health conditions faced by people are largely affected by the conditions where they are obliged to live in the days, weeks or months after a disaster. The quality of emergency tent has a great impact on human health and wellbeing. Therefore, mechanical properties of a tent fabric will be vital for sufferers. Since these tents are used under natural environment, tent fabrics have to face with natural exposures that force the mechanical strength of the fabric. One of the most important of these effects is UV exposure. It is known that fabrics lose their strength under UV light. In this study ammonium dihydrogen phosphate (ADP) coated $100 \%$ cotton tent fabrics were aged under UV exposure $\left(35 \mathrm{~W} / \mathrm{m}^{2}\right)$ for $0,250,500$ and 750 hours. Due to cellulose UV degradation mechanism exhibits oxidation of hydroxyl side groups and rupture of glycosidic bonds between cellulose units, tent fabric lost $40 \%$ of its tensile strength and $70 \%$ of its tearing strength compared to unaged fabric after 500 hours of UV aging process. FTIR (Fourier Transform Infrared Spectroscopy) analysis and SEM analysis were also held to investigate the degradation mechanism.
\end{abstract}

\section{ARTICLE HISTORY}

Received: 09.11.2018

Accepted: 14.04.2019

\section{KEYWORDS}

Tent fabrics, mechanical properties, tensile strength, fiber deterioration, UV aging

\section{INTRODUCTION}

Millions of people around the globe have had their lives disrupted by disasters. The provision of emergency shelter is a last resort when no other solution can be found for homeless people. Therefore, emergency tents must exhibit high strength against environmental conditions and exposures. Physical properties of emergency tents are directly related to the living standards of the users $[1,2]$.

One of the most important problems faced by emergency tents is UV exposure. Tents are constantly exposed to UV exposure as they remain under the sun light during the day. Since UV radiation degrades the molecular chains of the fabric material, tent fabric loses its strength over time [3].
The phenomenon of 'weathering' of polymeric materials is usually caused by a complex series of chemical reactions initiated by the absorption of ultra-violet light which ultimately result in the deterioration of the physical properties of the polymer [4].

The deterioration of polymers in outdoor weathering is caused primarily by sunlight, especially ultraviolet radiation. Sunlight reaching the earth is filtered through the atmosphere, removing shorter wave-lengths up to 280-310 $\mathrm{nm}$ before it reaches the surface of the earth. Beyond 380$400 \mathrm{~nm}$, the light becomes visible to the human eye. Thus, ultraviolet effects on polymers result primarily from wavelengths of approximately $300-400 \mathrm{~nm}$, which is $\sim 5 \%$ of the total solar radiation reaching the earth. The sun has an

To cite this article: Temel E, Bozdoğan F, Mizmizoğlu D. 2019. Structural investigation of UV aged tent fabrics. Tekstil ve Konfeksiyon 29(3), 246-252. 
approximate Boltzmann distribution of energy with a peak maximum at a wavelength of approximately 400-500 nm. However, the shorter wavelengths are not available at the earth's surface because they are absorbed by the ozone layer in the upper atmosphere. As a general rule, only light having a wavelength exceeding $300 \mathrm{~nm}$ reaches the earth's surface. This restricts the number of reactions which may occur [5].

Polymers such as plastics and rubbers consist of long molecular chains. These can vary in length, complexity and orientation, and these factors all contribute to the overall material behavior. Specific polymers possess specific chemical groups and bonds in their structure. These different chemical groups absorb differing amounts of energy. Unfortunately, most of these chemical groups have big absorbance within the UV spectrum. Furthermore, ultraviolet can cause breakdown of many polymer [6]. Figure 1, demonstrates some of the typical chemical groups and their absorption energies. Table 1, demonstrates ultraviolet wave lengths for typical commercial polymers.

Pure native cellulose absorbs UV radiation strongly between 200 and $300 \mathrm{~nm}$, but only very weakly up to 400 nm. Two pathways are important in cellulose degradation: oxidation of the hydroxyl side groups (changes in the color, polarity, solubility and water absorption-desorption properties) and rupture of the glycosidic bonds between cellulose units [7].

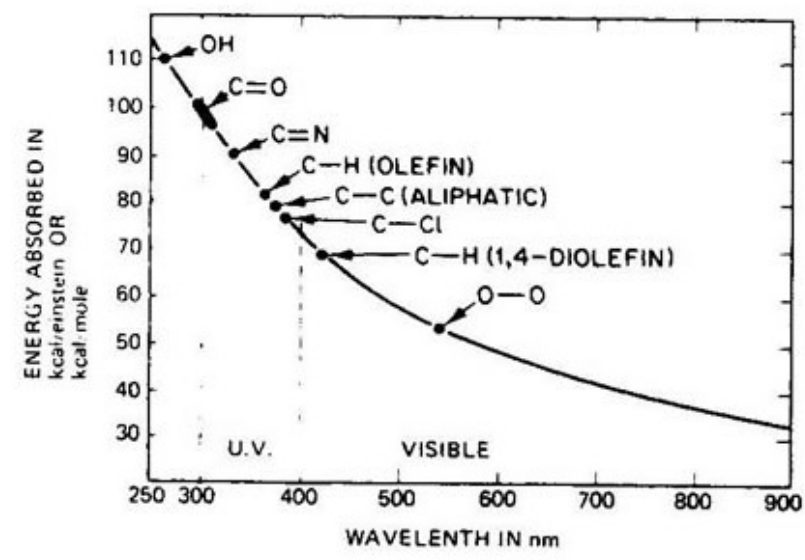

Figure 1. UV absorbtion energies and wavelengths of chemical groups [6].

Table 1. Ultraviolet wavelengths for typical polymers [5].

\begin{tabular}{lc}
\hline \multicolumn{1}{c}{ Polymer } & $\begin{array}{c}\text { Ultraviolet wavelength of } \\
\text { maximum sensitivity } \\
\text { (nm) }\end{array}$ \\
\hline Polyester & 325 \\
Polystyrene & 318 \\
Polyethylene & 300 \\
Polypropylene & 310 \\
Polymethyl Methacrylate & $290-315$ \\
Polyformaldehyde & $300-320$ \\
\hline
\end{tabular}

Hence the addition of energy via UV photons can produce significant absorptions of energy by the material and if the energy is sufficient can lead to breaking of the molecular bonds, effectively cutting the molecular chains. This situation leads to a reduction in molecular weight and subsequent loss in elastic behavior, cracking and general reduction in the mechanical properties [6].

The chemical changes caused by short-term UV irradiation are confined to fibers at the fabric surface and UV is unable to penetrate beyond the surface to weaken the bulk fibers responsible for the mechanical strength. This has enabled specific treatment in several areas [8].

UV degradation impact of a fabric may be affected by many textile properties. These parameters include mass per unit area, fiber type, yarn construction, finishing process and coloration process etc. [9]. Nevertheless, the most important factor affecting the fabric strength is UV exposure duration.

The physical specifications required for emergency tent fabrics are provided in official standards. However, the values in these standards indicate performances of fabrics not aged in ambient conditions. It should be noted that these fabrics are used in harsh environmental conditions and must exhibit the same/sufficient physical performance throughout the duration of use.

Therefore, in this study tent fabrics were aged under UV exposure for different periods and investigated their mechanical properties. Further to that, the degradation mechanism due to UV exposure is explained by internal structure analysis.

\section{MATERIAL AND METHOD}

In this study the aim is to investigate the time dependent strength change of emergency tent fabric after UV exposure. For this purpose, ammonium dihydrogen phosphate (ADP) coated 100\% cotton tent fabrics were aged in a UV aging cabin for 250, 500 and 750 hours. After aging process, aged fabrics and unaged tent fabric were conducted to tensile strength tests, tearing strength tests and air permeability tests. Tensile strength and tearing strength tests were performed on Zwick Universal Tensile Testing Machine by using TS EN ISO 13934-1 and TS EN ISO 13937-2 test standards respectively. Tearing strength test was also conducted to test samples on Elmendorf Ballistic Pendulum Tear Tester by using TS EN ISO 13937-1 test standard. Air permeability test were applied on TEXTEST FX 3300 Air Permeability Tester under $200 \mathrm{~Pa}$ air pressure. Furthermore, aging and degradation mechanisms of tent fabrics were also investigated by inner structure analyses. For this purpose, FTIR (Fourier Transform Infrared Spectroscopy) analyses were performed on aged and unaged tent fabrics to determine the structural changes the potential application of UV technology as a surface- 
between chemical bonds and groups. FTIR analyses were applied on Perkin Elmer FTIR Spectrometer. In order to observe fiber structural decomposition, SEM (Scanning Electron Microscope) analyses were applied by Thermo Scientific Apreo S SEM equipment. After UV exposure, color changes were occurred on fabrics. Fabric color alteration and yellowing degrees were also investigated by HunterLab UltraScan Pro Spectrophotometer according to ASTM E 313 standard.

The detailed description of the test material is given below in Table 2 .

Aging process was applied to test materials on Prowhite UV Test Box under 35 watt $/ \mathrm{m}^{2}$ light intensity for 250,500 and 750 hours.

Table 2. Description of test material

\begin{tabular}{ll}
\hline Property & Description \\
\hline Material & $100 \%$ cotton \\
Weaving pattern & $1 \mathrm{x} 1$ plain weave \\
Warp density & $20 \mathrm{ends} / \mathrm{cm}$ \\
Weft density & $11 \mathrm{ends} / \mathrm{cm}$ \\
Mass per unit area & $580 \mathrm{~g} / \mathrm{m}^{2}$ \\
Coating material & Ammonium dihydrogen phosphate \\
& (ADP) \\
\hline
\end{tabular}

\section{RESULTS AND DISCUSSION}

$0,250,500$ and 750 hours aged 100\% cotton tent fabrics were conducted to tensile strength, tear strength and air permeability tests. Test results are given below in Table 3 and Table 4.

When the effect of the UV exposure duration on tensile strength is examined, it can be denoted that increase in exposure time results in loss in tensile strength both in warp and weft direction. It is thought that, the result mainly depends on deterioration of hydroxyl side groups and rupture of the glycosidic bonds between cellulose units as Wypych mentioned in his study. He also stated that deterioration of hydroxyl side groups cause change in material color [7]. In Figure 3, it can be clearly seen that, the sample that was exposed to the maximum UV light was the sample that was most yellowish and darkest. Nevertheless, according to color analysis results (Table 5), no significant color changes between 500 and 750 hours was observed. Furthermore, when the color measurement results are examined in Table 6 , it is seen that the fabric treated for 500 hours has the same yellowing rate as the fabric treated with 750 hours. Again, according to the color measurements in Table 6; 750 hours of processed fabric became darker than 500 hours. It's thought that this situation emphases, the effect of UV exposure after 500 hours is significantly reduced. Although yellowing mechanism has stopped, the degradation mechanism has continued slightly. Similarly, when the strength loss values in Figure 2 are examined, no significant loss of strength is observed in the samples after 500 hours.

As all specimens were considered, no significant difference is observed between the elongation values of the samples, except warp direction for unaged sample. Since the unaged sample was not degraded and the test was performed in warp direction, unaged sample showed very high tensile strength values. For that reason, the elongation value is thought to be high. As work of rupture values were evaluated, it can be clearly seen that, work of rupture values highly depend on tensile strength and breaking elongation values. Therefore, it can be pointed out that the shorter the sample exposed to UV degradation, the higher work of rupture value has.

Table 3. Tensile strength test results of samples

\begin{tabular}{|c|c|c|c|c|c|c|}
\hline \multirow[t]{2}{*}{ Samples } & \multicolumn{2}{|c|}{$\begin{array}{l}\text { Tensile strength } \\
\text { (N) }\end{array}$} & \multicolumn{2}{|c|}{$\begin{array}{c}\text { Elongation } \\
(\%)\end{array}$} & \multicolumn{2}{|c|}{ Work of rupture (N.mm) } \\
\hline & $\begin{array}{c}\text { Warp } \\
\text { direction }\end{array}$ & $\begin{array}{c}\text { Weft } \\
\text { direction }\end{array}$ & $\begin{array}{c}\text { Warp } \\
\text { direction }\end{array}$ & $\begin{array}{c}\text { Weft } \\
\text { direction }\end{array}$ & $\begin{array}{c}\text { Warp } \\
\text { direction }\end{array}$ & $\begin{array}{c}\text { Weft } \\
\text { direction }\end{array}$ \\
\hline Unaged & 2297.16 & 1263.70 & 22.19 & 9.63 & 21477.00 & 5008.00 \\
\hline 250 hours treated & 1551.31 & 934.40 & 17.94 & 8.62 & 12037.75 & 3172.00 \\
\hline 500 hours treated & 1330.84 & 777.54 & 17.01 & 7.99 & 10167.75 & 2510.75 \\
\hline 750 hours treated & 1150.75 & 682.62 & 15.95 & 7.65 & 9765.00 & 1916.75 \\
\hline
\end{tabular}

Table 4. Tear strength and air permeability test results of samples

\begin{tabular}{lccccc}
\hline & \multicolumn{2}{c}{$\begin{array}{c}\text { Tear strength } \\
\text { (Trouser tear) } \mathbf{( N )}\end{array}$} & \multicolumn{2}{c}{$\begin{array}{c}\text { Tear strength } \\
\text { (Ballistic pendulum) (N) }\end{array}$} & $\begin{array}{c}\text { Air } \\
\text { permeability } \\
\left(\mathbf{l} / \mathbf{m}^{\mathbf{2}} / \mathbf{s}\right)\end{array}$ \\
\cline { 2 - 5 } & $\begin{array}{c}\text { Warp } \\
\text { direction }\end{array}$ & $\begin{array}{c}\text { Weft } \\
\text { direction }\end{array}$ & $\begin{array}{c}\text { Warp } \\
\text { direction }\end{array}$ & $\begin{array}{c}\text { Weft } \\
\text { direction }\end{array}$ & 12.49 \\
Unaged & 34.18 & 42.62 & 38.58 & 57.63 & 12.88 \\
$\mathbf{2 5 0}$ hours treated & 23.53 & 26.73 & 29.70 & 39.02 & 13.28 \\
$\mathbf{5 0 0}$ hours treated & 10.93 & 14.92 & 25.27 & 32.13 & 12.67 \\
750 hours treated & 9.88 & 13.55 & 21.39 & 29.91 & \\
\hline
\end{tabular}




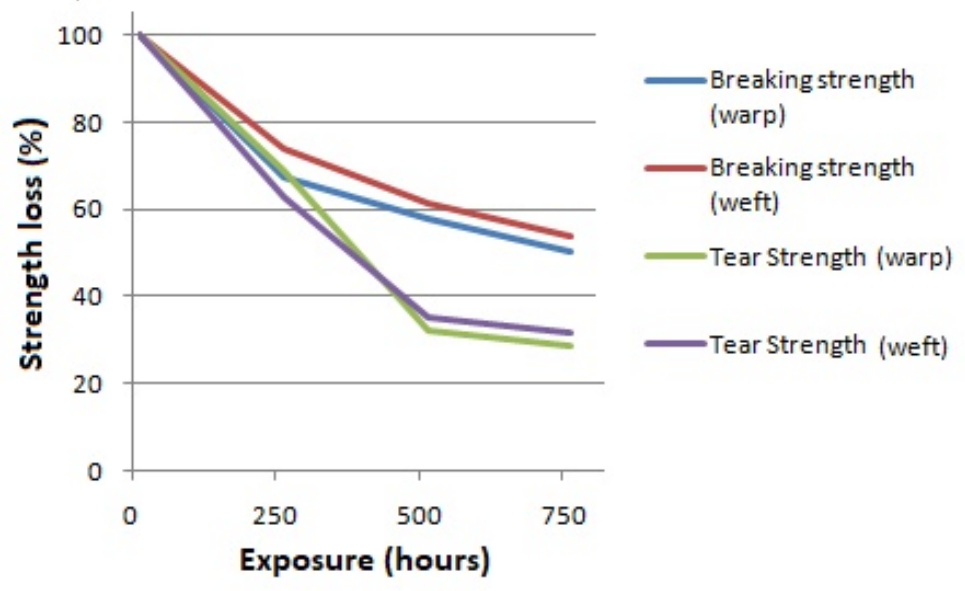

Figure 2. Time dependent strength loss (\%) of samples

Table 5. Color changes between UV treated fabrics

\begin{tabular}{lcc}
\hline & \multicolumn{2}{c}{ Color change $(\Delta \mathrm{E})$} \\
\hline & According to unaged sample & According to 250 hours treated sample \\
$\mathbf{2 5 0}$ hours treated & 37.63 & 0.00 \\
$\mathbf{5 0 0}$ hours treated & 41.41 & 5.77 \\
$\mathbf{7 5 0}$ hours treated & 39.97 & 5.57 \\
\hline
\end{tabular}

Table 6. Results of color measurements

\begin{tabular}{lcccc}
\hline & $\mathbf{L}^{*}$ & $\mathbf{a}^{*}$ & $\mathbf{b}^{*}$ & Yellowness Index \\
\hline Unaged & 86.25 & 1.89 & 9.18 & 19.88 \\
250 hours treated & 64.67 & 11.86 & 37.90 & 85.92 \\
$\mathbf{5 0 0}$ hours treated & 59.10 & 13.57 & 38.01 & 96.05 \\
750 hours treated & 58.92 & 12.69 & 36.21 & 94.49 \\
\hline
\end{tabular}

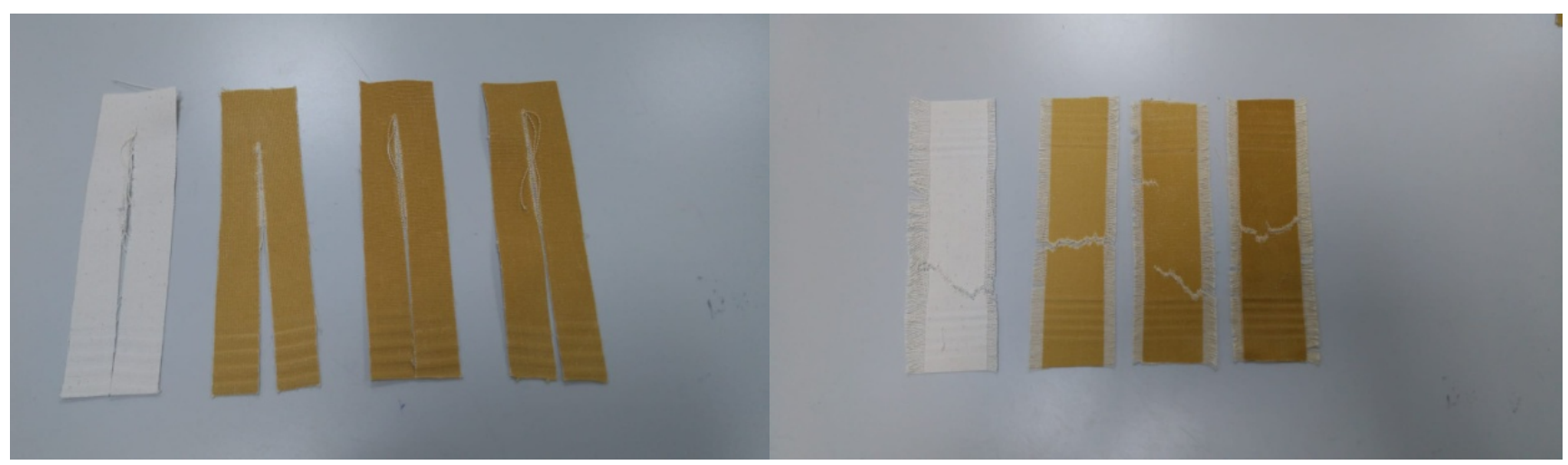

(a)

(b)

Figure 3. Samples that were conducted to tearing (a) and breaking (b) strength tests after UV exposure for 0, 250, 500 and 750 hours respectively.

When the ballistic pendulum and trousers tearing strength test results are examined, it can be stated that, the fabric the most exposed to UV degradation has the most loss of tearing strength, as expected. This situation is also associated with deterioration of hydroxyl side groups and rupture of the glycosidic bonds between cellulose units as mentioned above.

When air permeability test results are examined, it was determined that samples demonstrated nearly same air permeability test values with $12-13\left(1 / \mathrm{m}^{2} / \mathrm{s}\right)$. The ADP coating material on the fabric provides the fabric flame retardancy and waterproof properties. For that reason, fabric coating also limits and affects the air permeability properties. As the air permeability test results were evaluated, it was revealed that, UV exposure did not cause a remarkable degradation on fabric coating. Therefore, no significant change was observed on air permeability properties. FTIR analysis also support that the coating material is not damaged. 
In order to investigate degradation mechanism, FTIR analyses were conducted to UV treated samples. And the FTIR spectra of these samples are given in Figure 4.

FTIR spectrum given in Figure 4 shows the characteristic peaks of both cellulose and ammonium dihydrogen phosphate. Some peaks of ammonium dihydrogen phosphate and cellulose create overlaps, while some peaks exhibit characteristic vibrations. Vibration peaks appear around $3200-3300 \mathrm{~cm}^{-1}$ pointed out $\mathrm{O}-\mathrm{H}$ stretching of both cellulose and ADP [10-12]. The peaks at region around $1430 \mathrm{~cm}^{-1}$ indicate the N-H bonding stretching of ADP and $\mathrm{CH}_{2}$ vibrations of cellulose [13, 14]. Another group of overlapping peaks could be seen around 1000-1100 $\mathrm{cm}^{-1}$. These multiple peaks are stated as both P-O vibrations of ADP and C-O vibrations of cellulose [12, 15]. The vibration peaks appeared around $1640 \mathrm{~cm}^{-1}$ and $2400 \mathrm{~cm}^{-1}$ indicated existence of $\mathrm{N}-\mathrm{H}$ and $\mathrm{P}=\mathrm{O}$ bending vibrations of ADP respectively $[16,17]$.

It is stated above that, two pathways are important in cellulose degradation: oxidation of the hydroxyl side groups and rupture of the glycosidic bonds between cellulose units [7]. As seen in Table 6, deterioration of hydroxyl side groups caused color change from white to yellow in the samples. This situation can also be observed in FTIR diagrams. The peaks responsible for the hydroxyl groups in the cellulose structure are displayed at around $3200 \mathrm{~cm}^{-1}$. In Figure 4, it was determined that the decomposition of the hydroxyl structure appeared as a vibration increase in FTIR spectra.

Glycosidic bonds are linkages that hold together cellulose units. In the FTIR spectra the band at 1130-1160 $\mathrm{cm}^{-1}$ assigned to glycosidic bond stretching vibrations [18]. When the UV exposed samples were examined, it was observed that the vibration peak was stated in the spectrum of $1155 \mathrm{~cm}^{-1}$. However, when the exposure duration of the samples increased, this peak was gradually disappeared (Figure 4).

The effects of UV exposure on the appearance of the cotton tent fabrics was observed by SEM. And the images show distinctive stages of degradation (Figure 5). The micrograph of the unaged fiber reveals a uniform and smooth surface, but as the exposure time increases, a coarser and cracked texture begins to emerge, and 750 hours of UV exposure can produce dramatic erosion on the fiber surface.

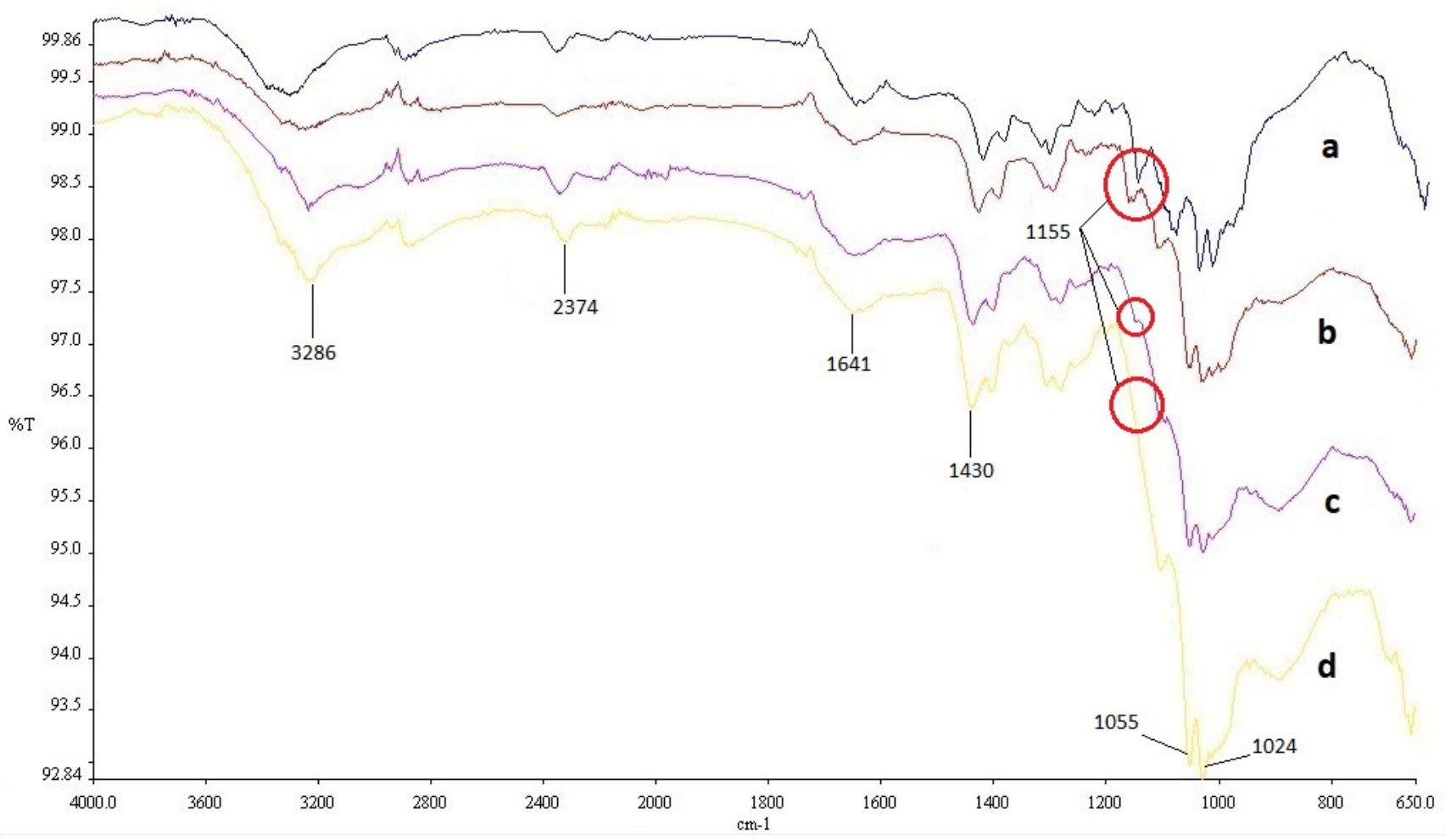

Figure 4. FTIR analyses of fabric samples: (a) unaged, (b) 250 hours treated, (c) 500 hours treated, (d) 750 hours treated 


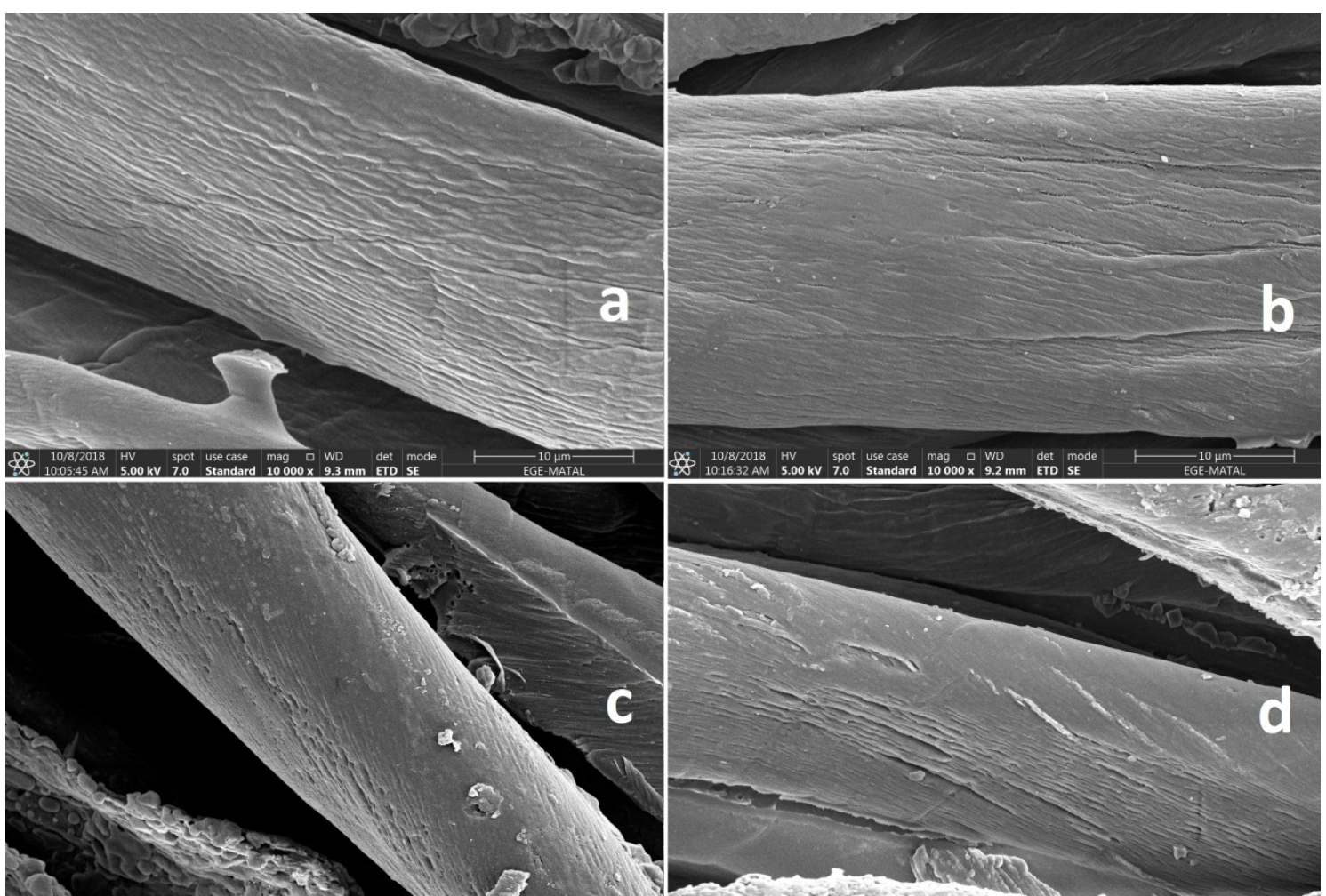

Figure 5. $10.000 \mathrm{X}$ magnified SEM images of samples. (a) Unaged, (b) 250 hours treated, (c) 500 hours treated, (d) 750 hours treated.

\section{CONCLUSION}

Sunlight, especially ultraviolet radiation can cause massive degradation on polymers. Therefore, fabrics which are exposed to sunlight for a long time are under the risk of mechanical disruption. Since tents are equipments that are used under sunlight, tent fabrics are also among those at risk.

Cellulose absorbs UV radiation strongly between 200-300 $\mathrm{nm}$, and this gap is involved by the ultraviolet region that reaches the world from atmosphere. In this study, ADP coated $100 \%$ cotton tent fabrics were aged under UV exposure in a UV cabin with $35 \mathrm{~W} / \mathrm{m}^{2}$ light intensity for 250,500 and 750 hours. After aging process, mechanical strength changes were compared upon unaged tent fabric. In addition, internal structure changes and degradation mechanisms were investigated by FTIR and SEM analyses.

Due to cellulose UV degradation mechanism exhibits oxidation of hydroxyl side groups and rupture of glycosidic bonds between cellulose units, tent fabric lost $40 \%$ of its tensile strength and $70 \%$ of its tearing strength compared to unaged fabric after 500 hours of UV aging process (Figure 2). This situation also corresponds to the loss of $1155 \mathrm{~cm}^{-1}$ peak in the FTIR spectra depending on the UV exposure time. Although there was no significant change in "strength loss" was observed after 500 hours. Tensile strength loss reached $50 \%$ and tear strength reached $75 \%$ at the end of 750 hours (Figure 2).

Degradation of hydroxyl side groups also cause color change from white to yellow as stated in Table 6. However, after 500 hours, the yellowing of the fabric has ended and the color has become darker (Table 6). It's thought that, this situation mainly depends on the end of yellowing mechanism, but the continuation of the degradation mechanism after 500 hours. The time-dependent changes in the FTIR spectra of the $\mathrm{OH}$ groups that cause color change can also be observed as an increment in $3286 \mathrm{~cm}^{-1}$ peak.

The fact that there is no change in the air permeability properties of the fabric after 750 hours of UV exposure indicates that, there is no remarkable damage existed on the coating structure of treated fabrics.

\section{REFERENCES}

1. Manfield P. 1999. A comparative study of temporary shelters used in cold climates. Martin Centre for Architectural and Urban Studies Department of Architecture, Cambridge University.

2. Crawford C, Manfield P, McRobie A. 2005. Assessing the thermal performance of an emergency shelter system. Energy and Buildings $37,471-783$.
3. De P, Sankhe M D, Chaudhar SS, Mathur MR. 2005. UV-resist, water-repellent breathable fabric as protective textile. Journal of Industrial Textiles 34(4), 209 - 222.

4. Guillet JE. 1972. Fundamental Processes In The UV Degradation and Stabilization Of Polymers. In Rado R, Chemical transformation of polymers. Elsevier, 135-144. 
5. Deanin RD, Orroth SA, Eliasen RW, Greer TN. 1970. Mechanism of ultraviolet degradation and stabilization in plastics. Polymer Engineering \& Science 10(4), 228-234.

6. http://www.drb-mattech.co.uk/uv\%20degradation.html

7. Wypych G. 2015. Handbook of UV degradation and stabilization. ChemTec Publishing

8. Millington KR. 2000. Comparison of the effects of gamma and ultraviolet radiation on wool keratin. Coloration Technology 116(9), 266-272.

9. Kursun S, Ozcan G. 2010. An investigation of UV protection of swimwear fabrics. Textile Research Journal 80(17), 1811-1818.

10. Takacs E, Wojnárovits L, Bors J, Földvár C, Hargittai P, Zöld O 1999 Effect of $\gamma$-irradiation on cotton-cellulose. Radiation Physics and Chemistry 55(5-6), 663-666.

11. Ciolacu D, Kovac J, Kokol V. 2010. The effect of the cellulosebinding domain from clostridium cellulovorans on the supramolecular structure of cellulose fibers. Carbohydrate Research 345(5), 621-630.

12. Jegatheesan A, Murugan J, Neelagantaprasad B, Rajarajan G. 2012. FTIR, XRD, SEM, TGA investigations of ammonium dihydrogen phosphate (ADP) single crystal. International Journal of Computer Applications 53(4), 15-18.

13. Colom X, Carrillo F, Nogués F, Garriga, P. 2003. Structural analysis of photodegraded wood by means of FTIR spectroscopy. Polymer Degradation and Stability 80(3), 543-549.
14. Rajesh P, Ramasamy P. 2009. Growth of dl-malic acid-doped ammonium dihydrogen phosphate crystal and its characterization. Journal of Crystal Growth 311(13), 3491-3497.

15. Wattanakornsiri A. Tongnunui S. 2014. Sustainable green composites of thermoplastic starch and cellulose fibers. Songklanakarin Journal of Science \& Technology, 36(2), 149-161.

16. Shingade BA, Sawadh PS, Rewatkar KG. 2016. Synthesis of different parameters and NLO properties of a new mixed L-Leucine doped in ammonium dihydrogen phosphate crystals. International Journal of Engineering Research \&Technology 4(30).

17. Renganayaki V, Syamala D, Sathyamoorthy R. 2012. Growth, Structural and spectral studies on pure and doped ammonium dihydrogen phosphate (ADP) single crystals. Archives of Applied Science Research 4(3), 1453-1461.

18. Nikonenko NA, Buslov DK, Sushko NI, Zhbankov RG. 2000. Investigation of stretching vibrations of glycosidic linkages in disaccharides and polysaccarides with use of IR spectra deconvolution. Biopolymers: Original Research on Biomolecules 57(4), 257-262. 